Int. J. Electrochem. Sci., 12 (2017) 10369 - 10380

\title{
Electrochemical Investigations of the Inhibitive Activity of a Pyridazinium Ionic Liquid for the Acid Corrosion of Carbon Steel
}

\author{
Sami BEN AOUN \\ Department of Chemistry, Faculty of Science, Taibah University, PO. Box 30002 Al Madinah Al \\ Munawarah, KSA. \\ E-mail: sbenaoun@ taibahu.edu.sa
}

doi: $10.20964 / 2017.11 .88$

Received: 22 August 2017 / Accepted: 23 September 2017 / Published: 12 October 2017

\begin{abstract}
A1-benzylpyridazin-1-ium bromide inhibition of the corrosion of carbon steel in molar hydrochloric acid has been investigated by electrochemical methods. MS20 adsorbed onto both hydrogen reduction and carbon steel dissolution active sites and acted as mixed-type inhibitor. The increasing MS20 concentrations induced increasing surface coverage and inhibition efficiency as concluded from both linear polarization and electrochemical impedance spectroscopy. In the former, a decreasing corrosion current and a positive corrosion potential shift were observed. While, in the latter, it led to an increasing charge transfer resistance and a decreasing double layer capacitance. The formation of a protective film was confirmed by SEM.
\end{abstract}

Keywords: Carbon steel; Corrosion; Ionic liquids; Linear polarization; Electrochemical impedance spectroscopy; Adsorption.

\section{FULL TEXT}

(C) 2017 The Authors. Published by ESG (www.electrochemsci.org). This article is an open access article distributed under the terms and conditions of the Creative Commons Attribution license (http://creativecommons.org/licenses/by/4.0/). 